\title{
Study of Endogenous Paramagnetic Centers in Biological Systems from Different Areas
}

\author{
Aygun Nasibova, ${ }^{1,2,3}$ Rovshan Khalilov ${ }^{10},{ }^{1,2,3}$ Huseyn Abiyev, ${ }^{4}$ Taras Kavetskyy, ${ }^{3,5,6}$ \\ Boris Trubitsin, ${ }^{7}$ Cumali Keskin (D), ${ }^{3,8}$ Elham Ahmadian (iD, ${ }^{9}$ and Aziz Eftekhari ${ }^{10,11,12}$ \\ ${ }^{1}$ Institute of Radiation Problems, Azerbaijan National Academy of Sciences, Baku, Azerbaijan \\ ${ }^{2}$ Department of Biophysics and Biochemistry, Baku State University, Baku, Azerbaijan \\ ${ }^{3}$ Joint Ukraine-Azerbaijan International Research and Education Center of Nanobiotechnology and Functional Nanosystems, \\ Drohobych, Ukraine \& Baku, Azerbaijan \\ ${ }^{4}$ Department of Biochemistry, Azerbaijan Medical University, Baku, Azerbaijan \\ ${ }^{5}$ Drohobych Ivan Franko State Pedagogical University, Drohobych, Ukraine \\ ${ }^{6}$ The John Paul II Catholic University of Lublin, Lublin, Poland \\ ${ }^{7}$ Department of Biophysics, Moscow State University, Moscow, Russia \\ ${ }^{8}$ Medical Laboratory Techniques Vocational Higher School of Healthcare Studies, Mardin Artuklu University, \\ Mardin 47200, Turkey \\ ${ }^{9}$ Kidney Research Center, Tabriz University of Medical Sciences, Tabriz, Iran \\ ${ }^{10}$ Stem Cell Research Center, Tabriz University of Medical Sciences, Tabriz, Iran \\ ${ }^{11}$ Drug Applied Research Center, Tabriz University of Medical Sciences, Tabriz 51664, Iran \\ ${ }^{12}$ Drohobych Ivan Franko State Pedagogical University, Drohobych, Ukraine
}

Correspondence should be addressed to Aziz Eftekhari; ftekhari@ymail.com

Received 28 September 2021; Revised 25 November 2021; Accepted 20 December 2021; Published 31 December 2021

Academic Editor: Zhong Chen

Copyright (c) 2021 Aygun Nasibova et al. This is an open access article distributed under the Creative Commons Attribution License, which permits unrestricted use, distribution, and reproduction in any medium, provided the original work is properly cited.

Plant leaves (Eldar pine (Pinus eldarica M.), fig (Ficus carica L.), and olive (Olea europaea L.)), collected in territories with different ecological conditions, of the Absheron Peninsula (Azerbaijan Republic) were studied by electron paramagnetic resonance spectroscopy (EPR). The generation of nanophase iron oxide magnetic particles in biological systems under the influence of stress factors was revealed. It was found that the process of biomineralization plays a role in the formation of biogenic iron oxide magnetic nanoparticles in plants and the generation of magnetite crystals in biological tissues, and stress factors have a stimulating effect on this phenomenon.

\section{Introduction}

Magnetic nanoparticles are widely found in many biological objects. Long before the synthesis of the first magnetic nanoparticles, they were discovered in natural biological complexes. It has been established that magnetic nanoparticles play a role in the metabolism and activity of living organisms [1-5]. The most common magnetic nanoparticles in living organisms are magnetite $(\mathrm{Fe} 3 \mathrm{O} 4)$ and maghemite $(\gamma$-Fe2O3). Magnetic nanoparticles can be found in bacteria and cells of higher living organisms [6-9]. It is believed that anisotropic magnetic nanoparticles in the cell can interact with the earth's magnetic field and transmit relevant information to other receptors in the body [10-13]. Since the application of magnetic nanoparticles in various fields is very important, it is very topical to carry out their synthesis by biological methods, as well as to clarify the role of biological processes in the synthesis of these nanoparticles.

The broad EPR signals characterizing iron oxide magnetic nanoparticles in the leaves and seeds of various 


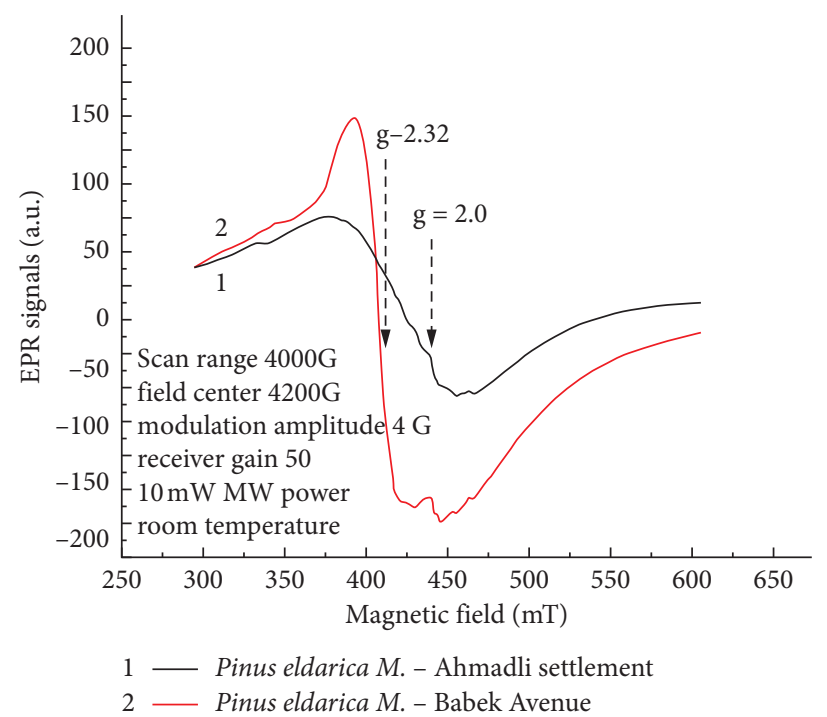

Figure 1: EPR spectra of Pinus eldarica M. leaves collected from Ahmadli settlement and Babek Avenue.

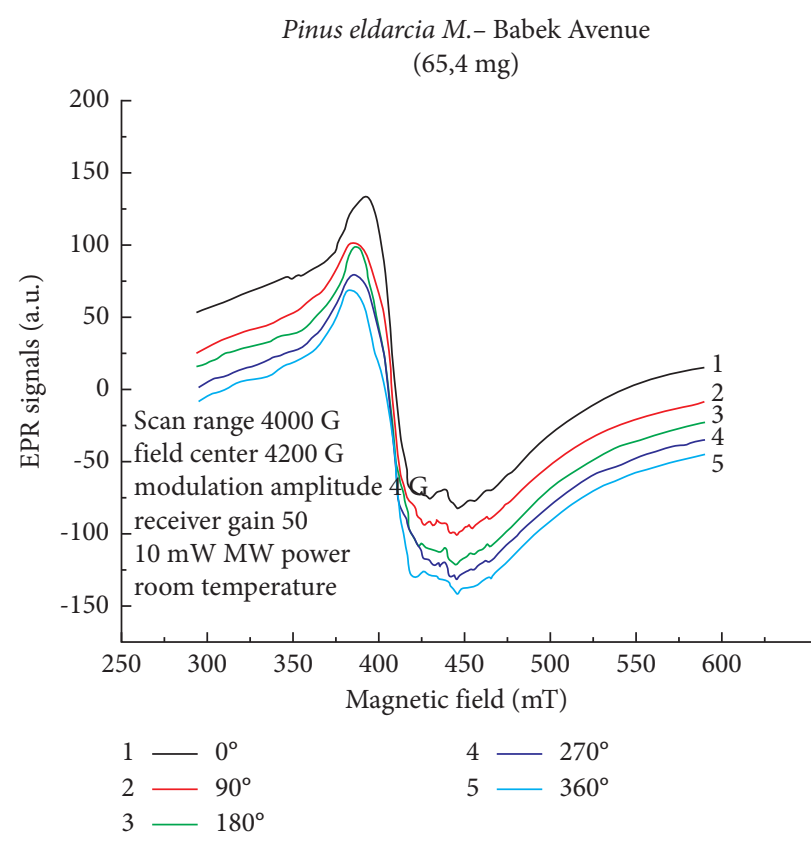

(a)

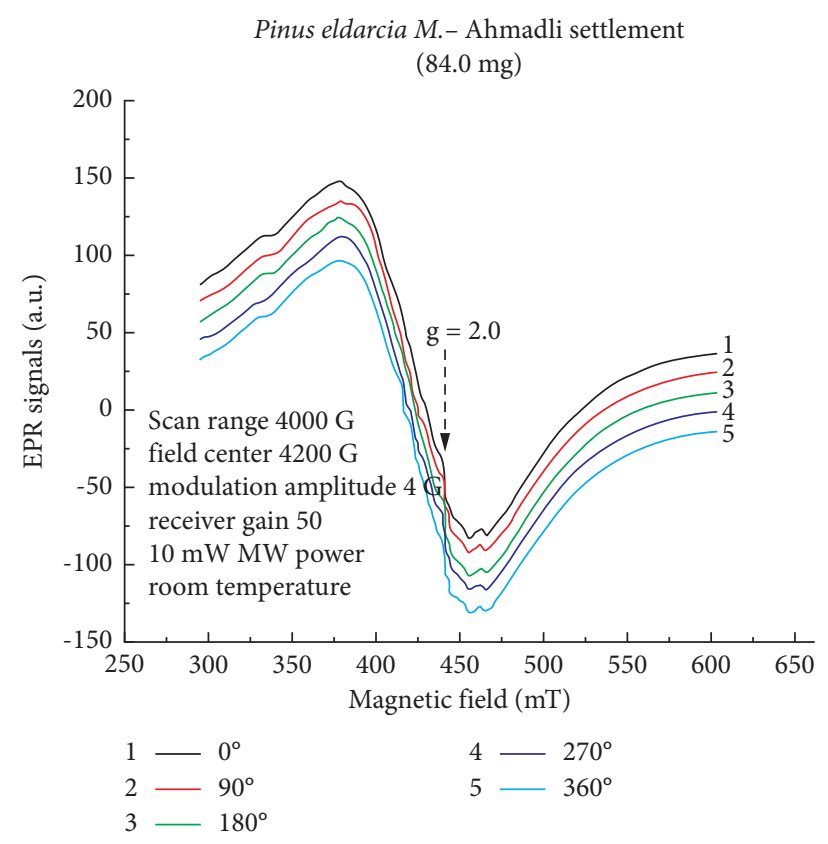

(b)

Figure 2: (a), (b) EPR spectra of Pinus eldarica M. leaf samples at different angular variations.

plants (autumn olive (Elaeagnus angustifolia L.), Syrian bean-caper (Zygophyllum fabago L.), camel-thorn (Alhagi Pseudalhagi), highland rush (Juncus trifidus L.), etc.) collected from radioactively contaminated areas of the Absheron Peninsula studied by us by EPR spectroscopy. The results of the experiments showed that the broad EPR signal, which characterizes the magnetic nanoparticles, is characteristic of leaf samples. Also, in the seeds, only EPR signals characterizing free radicals and manganese ions were observed. Radioactive contamination $(130-200 \mu \mathrm{R} / \mathrm{h})$ led to an increase in the amplitude of EPR signals in both cases [14].
In this work, the leaves of plants (Eldar pine (Pinus eldarica M.), fig (Ficus carica L.), and olive (Olea europaea L.)) collected from different areas according to their ecological status were studied comparatively by Electron Paramagnetic Resonance (EPR) spectroscopy. With help of this method, the generation of iron oxide magnetic nanoparticles in biological systems as a result of the process of biomineralization under the influence of stress factors has been discovered. It has been found that stress factors have a stimulating effect on this phenomenon. 


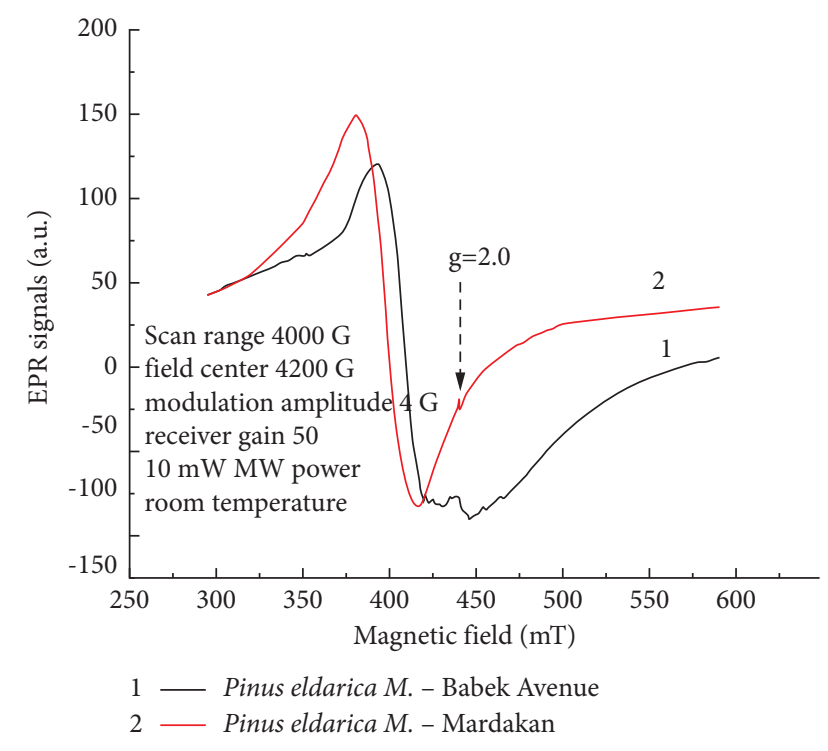

FIgURE 3: EPR spectra of Ficus carica L. (Mardakan) and Pinus eldarica M. (Babek ave.) leaves.

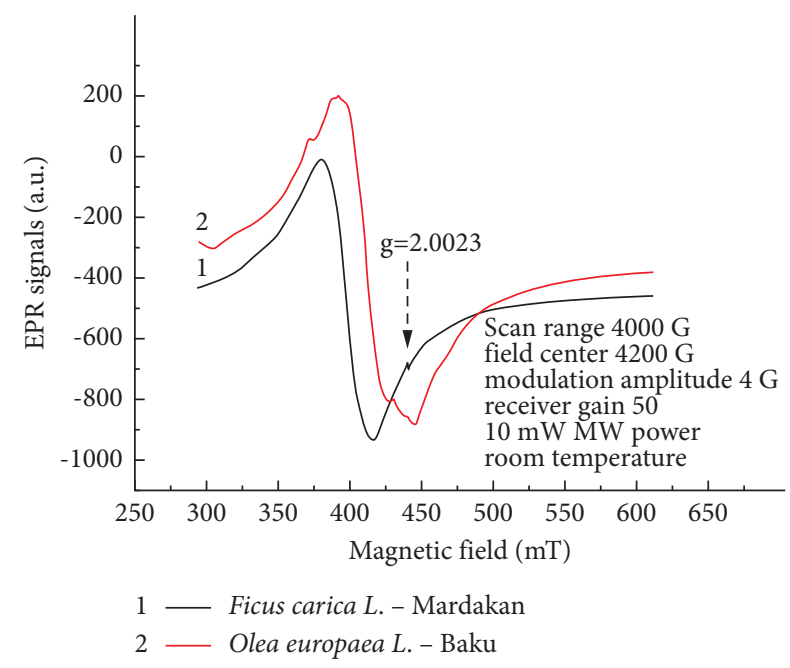

FIgUre 4: EPR spectra of Ficus carica (Mardakan) and Olea Europea L. (Baku) leaves.

\section{Materials and Methods}

From two different areas of the Absheron Peninsula in terms of the ecological situation (Ahmadli settlement and Babek Avenue) were collected leaves of Eldar pine (Pinus eldarica M.), fig (Ficus carica L.), and olive (Olea europaea L.)) for research. After the plants were dried at room temperature, their EPR spectra were recorded. A new approach based on the effect of biomineralization has been applied to these plants as a response to stress reduction and prevention. The spectra of plant leaves collected from different areas according to the degree of environmental pollution were studied with the help of an X-band EPR Spectrometer (BRUKER EMX, Germany, resolution: 1024 points, sweep width: 55000T).

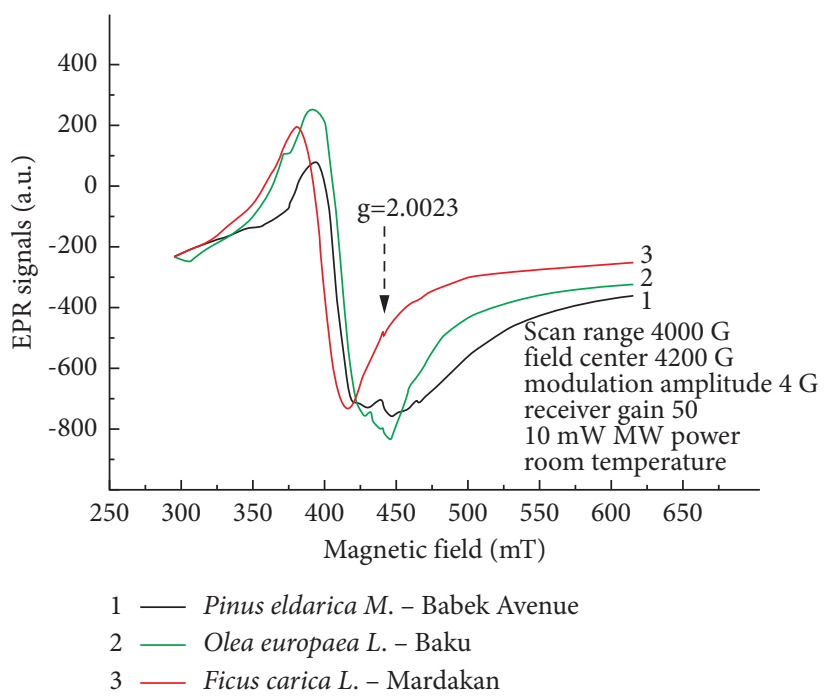

Figure 5: EPR spectra of leaves Pinus carica M., Ficus carica, and Olea Europea L.

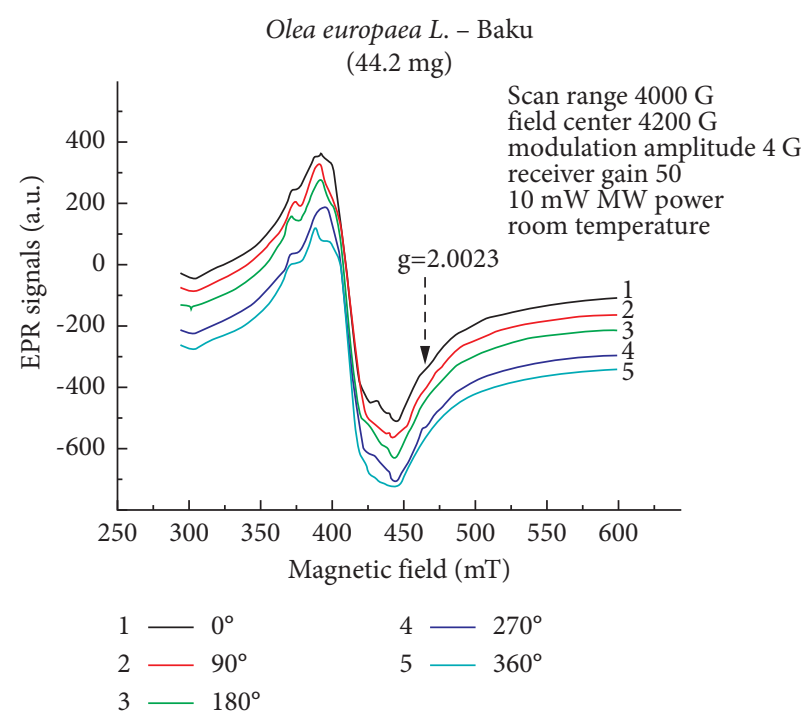

FIGURE 6: EPR spectra of Olea Europea L. leaves at different angular variations.

\section{Results and Discussion}

In experiments with Eldar pine (Pinus eldarica M.) leaves collected from different areas (Ahmadli settlement and Babek Avenue) according to the degree of environmental pollution, the generation of magnetic nanoparticles of biogenic origin was studied with the help of an X-band EPR spectrometer (BRUKER, Germany) (Figure 1).

Spectra of conifers (leaves) collected from the Eldar pine (Pinus eldarica M.) tree were recorded at room temperature. Two types of signals were detected in the recorded spectra, a free-radical signal $(g=2.0023)$ and a broad EPR signal ( $g=2.32 ; \Delta H=32 \mathrm{mT}$ ), characterizing nanophase iron oxide magnetic particles. The behavior of the signal parameters 
suggests that the samples collected from Babek Avenue contain more biogenic magnetic nanoparticles, and therefore, it is possible to assume that this area is more exposed to environmental pollution (Figure 1).

Angular variations were also studied in the samples. To determine the variation of the angle in the resonator, the glass ampoule in which the samples were placed was examined at different angles $\left(90^{\circ}, 180^{\circ}, 270^{\circ}\right.$, and $\left.360^{\circ}\right)$ (Figure 2 ). As a result, we observed a slight change in the shape and location of the EPR signal. In this case, the samples were normalized on unit mass.

Such behavior of signals has been found for magnetite (Fe3O4), maghemite $(\gamma$-Fe2O3), and superparamagnetic nanoparticles. This indicates that the paramagnetic centers responsible for the EPR signal have a complex structure.

At the same time, paramagnetic centers in the leaves of Olea Europea L. and Ficus carica L. trees have also been studied (Figures 3-5).

Based on the behavior of the parameters of the recorded signals, the EPR spectra of Eldar pine (Babek ave.) and fig (Mardakan) leaves, where more biogenic magnetic nanoparticles are formed, were compared. As a result, it was found that nanophase iron oxide particles are mostly formed in fig leaves as a result of stress factors (Figure 3). Later, EPR spectra of fig leaves and olive leaves were recorded at room temperature, and the generation of more magnetic nanoparticles in olive leaves was determined (Figure 4).

\section{Conclusions}

EPR studies with the leaves of three different tree plants in Absheron (Pinus eldarica M., Olea Europea L., and Ficus carica L.) have once again shown that, under stress, they generate signals characterizing iron oxide magnetic nanoparticles $(g=2.32 ; \Delta \mathrm{H}=40 \mathrm{mT})$. This result is of great importance in biomedical research.

The recorded EPR spectra showed that more iron oxide magnetic nanoparticles are generated in olive leaves. The study of the angular variations of the signals of olive leaves showed that this signal has a magnetic anisotropy (Figure 6). It was observed that the EPR signal shifted to the left when the ampoule containing the samples in the resonator of the spectrometer was rotated $90^{\circ}, 180^{\circ}, 270^{\circ}$, and $360^{\circ}$. Such behavior of signals has been found for magnetite $\left(\mathrm{Fe}_{3} \mathrm{O}_{4}\right)$, maghemite $\left(\gamma-\mathrm{Fe}_{2} \mathrm{O}_{3}\right)$, and superparamagnetic nanoparticles. This indicates that the paramagnetic centers responsible for the EPR signal have a complicated structure $[14,15]$.

It was found that the process of biomineralization plays a role in the formation of biogenically iron oxide magnetic nanoparticles in plants, in the generation of magnetite crystals in biological tissues, and stress factors have a stimulating effect on this effect. The effect of the influence of radiation factors discovered by us can be used in the biosynthesis of functional iron oxide nanoparticles applied in various fields. Detection of iron oxide nanoparticles by EPR signals can be used in biomedical research.

The intensity of EPR signals characterizing magnetic nanoparticles can be an indicator of the impact of stress factors (environmental pollution, radiation, UV radiation, etc.). The parameters of EPR signals give a reason to comment on the environmental situation in these areas. Studies by EPR spectroscopy have shown that this method is a very promising method for detecting the formation of magnetic nanoparticles of iron oxide in biological systems and can provide new information in the determination of pollution levels of natural systems, environmental assessment, and biomonitoring. The results of EPR research are informative for radioecological and radiobiological research.

\section{Data Availability}

The data used to support the findings of this study are available from the corresponding author upon request.

\section{Conflicts of Interest}

The authors declare no conflicts of interest.

\section{Acknowledgments}

Prof. Rovshan Khalilov and Dr. Aygun Nasibova would like to acknowledge the Baku State University and Institute of Radiation Problems, Azerbaijan National Academy of Sciences, Baku, Azerbaijan, for providing the platform to complete this research work.

\section{References}

[1] D. Prodan, C. Chanéac, and E. Tronc, "Adsorption phenomena and magnetic properties of $\gamma-\mathrm{Fe}_{2} \mathrm{O}_{3}$ nanoparticles," Journal of Magnetism and Magnetic Materials, vol. 203, no. 13, pp. 63-65, 1999.

[2] J. Kudr, Y. Haddad, L. Richtera et al., "Magnetic nanoparticles: from design and synthesis to real world applications," Nanomaterials, vol. 7, no. 9, p. 243, 2017.

[3] A. Figuerola, R. Di Corato, L. Manna, and T. Pellegrino, "From iron oxide nanoparticles towards advanced iron-based inorganic materials designed for biomedical applications," Pharmacological Research, vol. 62, no. 2, pp. 126-143, 2010.

[4] A. S. Arbab, L. A. Bashaw, B. R. Miller et al., "Characterization of biophysical and metabolic properties of cells labeled with superparamagnetic iron oxide nanoparticles and transfection agent for cellular MR imaging," Radiology, vol. 229, no. 3, pp. 838-846, 2003.

[5] E. Ahmadian, S. M. Dizaj, S. Sharifi et al., "The potential of nanomaterials in theranostics of oral squamous cell carcinoma: recent progress," TRAC Trends in Analytical Chemistry, vol. 116, pp. 167-176, 2019.

[6] E. Taylor and T. J. Webster, "Reducing infections through nanotechnology and nanoparticles," International Journal of Nanomedicine, vol. 6, pp. 1463-1473, 2011.

[7] C. S. Ciobanu, S. L. Iconaru, E. Gyorgy et al., "Biomedical properties and preparation of iron oxide-dextran nanostructures by MAPLE technique," Chemistry Central Journal, vol. 6, no. 1, p. 17, 2012.

[8] J.-H. Lee, J.-t. Jang, J.-s. Choi et al., "Exchange-coupled magnetic nanoparticles for efficient heat induction," Nature Nanotechnology, vol. 6, no. 7, pp. 418-422, 2011. 
[9] D. Yoo, J.-H. Lee, T.-H. Shin, and J. Cheon, "Theranostic magnetic nanoparticles," Accounts of Chemical Research, vol. 44, no. 10, pp. 863-874, 2011.

[10] A. Ito, M. Shinkai, H. Honda, and T. Kobayashi, "Medical application of functionalized magnetic nanoparticles," Journal of Bioscience and Bioengineering, vol. 100, no. 1, pp. 1-11, 2005.

[11] O. Veiseh, J. W. Gunn, and M. Zhang, "Design and fabrication of magnetic nanoparticles for targeted drug delivery and imaging," Advanced Drug Delivery Reviews, vol. 62, no. 3, pp. 284-304, 2010.

[12] J. Li, N. Menguy, E. Leroy, A. P. Roberts, P. Liu, and Y. Pan, "Biomineralization and magnetism of uncultured magnetotactic coccus strain THC-1 with non-chained magnetosomal magnetite nanoparticles," JGR Solid Earth, vol. 125, no. 12, 2020.

[13] O. Y. Gorobets, S. V. Gorobets, and Y. I. Gorobets, "Biogenic magnetic nanoparticles: biomineralization in prokaryotes and eukaryotes," Dekker Encyclopedia of Nanoscience and Nanotechnology, Teylor and Francis, New York, NY, USA, 2014.

[14] A. Nasibova, R. Khalilov, H. Abiyev, B. Trubitsine, and A. Eftekhari, "Identification of the EPR signals of fig leaves (Ficus carica L.)," Eurasian Chemical Communications, vol. 3, pp. 193-199, 2021.

[15] A. Alessi and F. Gelardi, "Electron paramagnetic resonance spectroscopy (EPR)," Spectroscopy for Materials Characterization, vol. 26, pp. 253-80, 2021. 